\title{
Always already post: subaltern epistemologies in cinema curation
}

Gabriel Menotti

\begin{abstract}
The notion of "post-cinema" derives from a modern understanding of media that frames cinema as a homogenous, exclusive totality. This paper proposes an epistemic approach more sensible to cinema's performative condition based on curatorial practices. It argues for curation as a form of enacted research distributed across the matrix of reproductive practices responsible for keeping the objective coherence of the medium. As such, curation would be able to access subaltern modes of knowledge and challenge the abyssal thinking prevailing within film and media studies.
\end{abstract}

\section{Keywords}

Curation, modernity, media reproduction, reproductive labor, subaltern knowledge.

\section{Curatorial insights}

In the introduction to his anthology Pré-Cinemas e Pós-Cinemas [Pre-Cinemas and PostCinemas], the late media theorist Arlindo Machado confesses to his initial difficulty in framing the volume. ${ }^{1}$ Pré-Cinemas e Pós-Cinemas meant to gather Machado's unpublished essays going in two different and seemingly contradictory directions. A part of the texts addressed early optical devices and cinema's celebrated ancestors; the other part, emerging forms of audiovisual media based on electronics and informatics. It was an unusual project for the mid-1990s, when most media research kept to very specific categories. How to turn this mishmash of topics into a cohesive book outline, the seasoned author wondered? The thread he saw connecting all the chapters was the omnipresence of cinema as an underlying reference. Lacking linearity and an overarching thesis, however, the book did not deal in cinema history proper. In fact, cinema was not really there. The medium only provided common epistemic grounds through which one could access other past and future audiovisual phenomena. A paradigm of sorts.

Machado's breakthrough came upon finding the book's title. The rhyming concepts compelled the integration of his collection of essays into a single piece of scholarship. The solution was not his own, though: he borrowed it from a cancelled project by the São Paulo Museum of Image and Sound (MIS-SP). The original Pré-Cinemas e Pós-Cinemas was conceived by Amir Labaki and Lucas Bambozzi, respectively the museum's director and video curator at the time, to be a show celebrating cinema's hundred-year anniversary in 1995. Much like Machado's book after it, the exhibition project capitalized on the

\footnotetext{
${ }^{1}$ Arlindo Machado, Pré-Cinema e Pós-Cinemas, São Paulo, Papirus, 1997.
} 
significance of the medium as a pretext to look outwards. The very idea of cinema would be stretched towards other technological practices and forms around it. Cinema, in the apex of its historical actuality, would be shown to be both older and more abundant than conventions dictate.

The MIS-SP exhibition never came to be, due to changes in the museum's board of directors. By acknowledging its inspiration in his book introduction, Machado implies backstage dialogues connecting scholarly and cultural labour. The recycling of curatorial argument into editorial structure asserts a reciprocity between the production of concepts and the reproduction of practices. At the same time, it reveals what academic investigation might owe to curatorial insights. The scholar, while able to intuit how cinema proliferates across other media, could not easily mobilize this self-differing condition for the benefit of his research. It did not come naturally to Machado the possibility of reconciling cinema's crystallized identity with the ever-growing constellation of moving image apparatus he was unearthing. Cultural agents managed to arrive earlier at this idea. They were so at ease with it, in fact, that they thought it best represented cinema in its centennial.

This anecdote illustrates an epistemic gap one might be tempted to attribute to the slow pace of academia. Science takes time. To arrive at certain proposals, scientists must examine their hypothesis to exhaustion. Other cultural practices - the arts - do not have to go through the same checks and balances, leaving curators at a deductive advantage. Curators might deploy extraordinary interpretations of the world quicker and more often than a scientist ever could. But how right can they be? The underlying suspicion is that the curatorial grasp on a given state of affairs might be as misguided as it is bold. Worse, following what Paul O'Neil identifies as the ascension of the "curatorial gesture" in the $1990 \mathrm{~s},{ }^{2}$ that curators could hijack the meaning of socio-cultural phenomena in order to create discursive orders of their own. Curators are not in the business of uncovering facts, after all, but rather of composing collections and displays.

The proposal I hope to advance in this paper calls for a complexification of these differences between academic and cultural work. My argument relies on a re-evaluation of truth conditions in modern science as well as of the role of method in knowledge production. Ultimately, I want to advocate for the scientific legitimacy of curatorial insights based on the particular relations that curators establish with their fields of activity. In doing so, I assume that the defining distinction between scholarly and curatorial approaches to academic research is not one of rigor, but rather of sensibilities. This does not mean to say that curators are more focused on their objects of knowledge than scholars. On the contrary, by virtue of practice, curatorial attention continually drifts from objects to their circumstances and vice-versa. While one curates for a screening, for example, a movie never exists on its own, but among every other that could take its place.

\footnotetext{
${ }^{2}$ Paul O’Neill, “The Curatorial Turn: From Practice to Discourse” dans Judith Rugg \& Michèle Sedgwick (dir.), Issues in Curating Contemporary Art and Performance, Bristol, Intellect, 2007, pp. 13-28.
} 
And the individual work does not occur by default either: its presence flickers across material transfers, institutional clearances, and other discursive acts that often fall within curatorial purview. These articulations call for an ecological awareness that suspends objective self-determination and makes the innate heterogeneity of the medium much more palpable.

The fact that any curatorial understanding might fall short of the rigor expected by academia is not surprising. Modern sciences are built over an objectivist epistemology running on atomization and disciplinarization. They categorically separate subjects from objects, as well as knowing from doing, and assign the ones exclusive power to decipher the meaning of the others. The observer must stand apart from the world. The distance supposedly allows theory its neutral, totalizing perspective. Curators cannot play this role properly because they are partial to the workings of their objects. Curatorial ways of knowing are thus incompatible with the universal subject of modernity. To reconcile their insights with these epistemic norms, curators must disavow their own situated position and conform it to the predominant discursive order.

The notion of Pré-Cinemas e Pós-Cinemas manifests this paradox. On the one hand, it invites us to partake in the curatorial awareness of the inherent transience of the medium. One gets to appreciate cinema less as an everlasting reality than as a momentary stage inbetween other phenomena - an entr'acte in history, as Siegfried Zielinski would say. ${ }^{3}$ Nonetheless, "Pré-Cinemas e Pós-Cinemas" simultaneously betrays an adherence to modern objectivism. While the term indeed translates a curatorial understanding of cinema, it frames this understanding as supplementary to cinema proper. In other words, the idea of Pré-Cinemas e Pós-Cinemas turns this curatorial perspective over cinema into a derivative category subordinated to a universal one. In doing so, this idea suppresses the fact that, from a curatorial perspective, any cinema is always already post.

The modern hierarchy of knowledges both reflects and calcifies structures of power within cinema. Once we follow the distribution of curatorial operations beyond certain figures of authority, we find a matrix of reproductive labour tasked with the maintenance of media practices and institutions. That means to say that many worldviews neutralized by a singular understanding of cinema tragically coincide with those of people responsible for keeping the medium operating smoothly and seamlessly, as if it were singular. By challenging universal objectivism, forms of curatorial thinking with cinema (instead of about it) may redeem these subject positions from subalternity, as well as affirm the ontological variability of media denied by epistemic subordination.

\section{Cinema has never been}

\footnotetext{
3 Siegfried Zielinski, Audiovisions: Cinema and Television as Entr'actes in History, Amsterdam, Amsterdam University, 1999.
} 
Bruno Latour once offered the world the perplexing assumption that "we have never been modern." The book that carries that title reads nowadays as a transitional piece in Latour's thought, extrapolating from his earlier ethnographic approach to science studies while sketching some of the grammar and methods leading to actor-network theory. Upon its release, however, Nous n'avons jamais été modernes stood as a resolute response to the consecration of the West in the aftermath of the fall of the Berlin wall. In a gesture of symmetric anthropology, Latour turned his attention to the "moderns" and dissected Modernity as a set of illusions "they" have about themselves "and want to generalize to everyone." 4 Here, beyond Latour's continuing interest in emancipating nonhumans, also lies a criticism of the normative violence underlying the epistemic project stemming from the European Enlightenment. A fiction central to Modernity, after all, is the idea that the European, largely white imperial subjects who constitute the "moderns" universally account for "us."

According to Latour, the illusion of Modernity is made operational by an unspoken "Constitution" that enables moderns to come to terms with "the double creation of a social context and a nature that escapes that very context." ${ }^{5}$ Latour traces the origins of the modern Constitution to the almost simultaneous developments of Thomas Hobbes' political philosophy and Robert Boyle's scientific method in the $17^{\text {th }}$ Century. Each of them devised modes of universal representation for, respectively, subjects of law and external truths. In so doing, political philosophy and the scientific method established concurrent branches for the government of subjects and objects. These two branches govern together by mutual exclusion, since they "possess authority only if they are clearly separated." 6 For Latour, the anthropological discrimination between "us" and "them," presumably along with other foundational dichotomies of Modernity, is an "exportation" of the ensuing Great Divide between humans and nonhumans. ${ }^{7}$

However, by calling our attention to "the language that transports politics outside of science," Latour indicates that the separation between these two categories might not be as clear-cut. ${ }^{8}$ He posits that political and scientific representation within Modernity are ultimately one and the same, in that both rely on networks of practices to filter each other out and uphold the universality of pure entities. The Constitution allows moderns to pretend that practices of purification, which create "entirely distinct ontological zones" for humans and nonhumans, are essentially distinct from those of translation, which create "hybrids of nature and culture." 9 Meanwhile, the moderns employ practices of translation to further extend and stabilize their networks of purification on an unprecedented scale. Thereby, they subsume foreign entities and impose their categories abroad. The imperial articulation of modern knowledge and power aims for global totality.

\footnotetext{
${ }^{4}$ Bruno Latour, We have Never Been Modern, Cambridge, MA, Harvard University, 1993, p. 133.

${ }^{5}$ Bruno Latour, ibid., p. 15.

${ }^{6}$ Bruno Latour, ibid., p. 27.

${ }^{7}$ Bruno Latour, ibid., p. 97.

${ }^{8}$ Bruno Latour, ibid., p. 16.

${ }^{9}$ Bruno Latour, ibid., p. 10.
} 
The modern art institution provides an operative model of this symmetry between purification and translation. The subtractive space of the modern art gallery, aptly described by Brian O'Doherty as the white cube, ${ }^{10}$ seeks to conciliate any entity with the objective ideals of a Greenbergian aesthetics. ${ }^{11}$ In actuality, the modern desire for "pure" forms cannot be fulfilled if not through this environmental bubble, which effectively abstracts a work from its making and neutralizes the context of its experience. As an effect of autonomous presence, the modern artwork exists within the confines of a network of white cubes. The generalization of the artwork's self-containment relies on the expansion of this network, which in turn depends on the conversion and maintenance of exhibition spaces equivalent to one another, as well as on the seamless transportation of the work into and across these spaces. Already in 1953, Alain Resnais, Chris Marker, and Ghislain Cloquet disclosed the potential violence of these practices in their documentary les Statues meurent aussi [Statues also Die]. Their film makes a case for the museological display as a continuation of colonial plunder by other means.

For Latour, the fall of the Berlin wall is the coronation of a stage when the West, destitute of any competing externality, can no longer sustain the internal contradictions of Modernity. Hybrids proliferate. "Our" incapacity to sort out increasingly complex entities in "the habitual, cartesian categories of nature, politics and discourse" undermines the modern Constitution. ${ }^{12}$ The emerging postmodernism is a symptom of "no longer believing in the guarantees [this Constitution] offers" and yet complying with a temporality dictated by modern classification principles. ${ }^{13}$ In that sense, to paraphrase Jacques Derrida, postmodernism would still be "captive of that metaphysical edifice it professes to overthrow." "The Latourian solution to the Modernity conundrum is the refusal of modern temporality, leading to a re-examination of history instead. One ought to admit that purification and translation have always been symmetrical forms of mediation, and that hybrids have always preceded the constitution of pure entities. Hence, contrary to "our" beliefs, "we" have never been modern. Having accepted nonmodernity, we are open to creating a new constitution committed "to providing representation to quasi-objects" 15 - which is arguably the project undertaken by actor-network theory and other flat ontologies. In so doing, we become able to substitute the single nature/culture divide by a plurality of continuous, nonmodern nature-cultures.

By the early 1990s, the ubiquity of mixed-media installations conveys a similar atmosphere of hybridity to the global artworld. Genres such as installation art and institutional critique forfeit any pretense of self-containment insofar as they disrupt the fabricated neutrality of the work presentation. Rosalind Krauss suggests that these artforms, alongside the emergence of video as a communication system, consolidate a

\footnotetext{
${ }^{10}$ Brian O'Doherty, Inside the White Cube: The Ideology of the Gallery Space, San Francisco, The Lapis Press, 1986.

${ }^{11}$ Clement Greenberg, Art and Culture: Critical Essays, Boston, Beacon Press, 1961.

${ }^{12}$ Bruno Latour, We have Never Been Modern, op. cit., p. 3.

${ }^{13}$ Bruno Latour, ibid., p. 46.

${ }^{14}$ Jacques Derrida, Of Grammatology, Baltimore \& London, The Johns Hopkins University, 1997, p. 19.

${ }^{15}$ Bruno Latour, We have Never Been Modern, op. cit., p. 139.
} 
post-medium condition dismissive of modern ideals. ${ }^{16}$ Accordingly, Krauss proposes to abolish the notion of "medium" from its modernist connotations. Her redefinition of medium as a recursive structure - a differential "layering of conventions" 17 - effectively acknowledges the practices of mediation constitutive of any given work's singularity. The awareness of these practices displaces our sense of media specificity from the pure physicality of the support to the variable circumstances of the site. The medium thus ceases to exist as a historical generalization. It is, in fact, as if the medium had never been.

Cinema occupies a central position in Krauss' reflection. As a technological aggregate, cinema initially resists the closure implied by any modernist definition of medium specificity. But the abstract notion of apparatus comes to provide a convenient substitute, enabling reductive treatments of the cinematographic medium. Film theory and filmmakers alike fixate on "apparatus" as an economic representation through which the coherent totality of cinema can be reached. Krauss describes how structural film's pursuit of the nature of cinema, for instance, sought to "sublate the internal differences within the filmic apparatus into a single, indivisible, experiential unit."18 This avant-garde and essentially modernist project informed the design of Anthology Film Archives' Invisible Cinema, the movie theater where the structural film pioneers convened in New York. Projected to foster the experience of film "itself," the Invisible Cinema meant to be as close a cinematographic equivalent of the white cube as possible. Formal purity was achieved, once again, through further mediation. Chairs were even partitioned to increase the spectators' sense of isolation from the circumstances of exhibition.

Krauss will find expressions of the medium's self-differential disposition in works by conceptual artist Marcel Broodthaers that recuperate the indeterminacy of early film. But one could as likely recognize cinema's multiplicity in mixed-media installations made in the 1970s, around the same time as the structural film classics. Works by members of the London Film-Makers' Coop, such as Malcolm LeGrice, Lis Rhodes, and William Raban, famously gesture at latent reconfigurations of the cinematographic apparatus while displacing the conventional features of film exhibition. In a deliberate reaction to television, the projection environments created by Hélio Oiticica and Neville D'Almeida for the series BLOCO-EXPERIENCIAS in COSMOCOCA - programa in progress (197374 ) advance the notion of "quasi-cinema." By simultaneously incorporating elements that could be considered pre- (slideshows, asynchronous soundtrack) and postcinematographic (props, performance instructions), the Cosmococas liberate the ontological insufficiency of media from the positive temporality of modernity. Quasicinema - "almost cinema" - is not a cinema to be, but rather cinema as the mess it actuality is. In a sense, it is a representation of the medium as a Latourian quasi-object.

The digitization of film fosters an acknowledgement of this same insufficiency within cinema proper. It is an "onset of higher orders of technology" that, as stated by Krauss, brings to the fore the inner complexity of the techniques it supersedes. ${ }^{19}$ But digitization

\footnotetext{
${ }^{16}$ Rosalind Krauss, "A Voyage on the North Sea": Art in the Age of Post-Medium Condition, London, Thames \& Hudson, 2000.

${ }^{17}$ Rosalind Krauss, ibid., p. 53.

${ }^{18}$ Rosalind Krauss, ibid., p. 30.

${ }^{19}$ Rosalind Krauss, ibid., p. 53.
} 
is also the fall of the Berlin wall that has sent cinema in a triumphant state of ontological disarray. The notion of "post-cinema" re-emerges within this context as a way of addressing the dissolution of cinematographic work among other forms of media cultural practice. In order to make sense of the hybrids stemming from this process, however, "post-cinema" realigns the medium to modern temporality. By deploying cinema as a stable reference to categorize that which exceeds it, "post-cinema" essentializes cinema and reinstates dichotomies that fail to consider the innate multiplicity of the singular medium. It reinforces by contrast the idea of an objectively coherent, universal cinema.

In that sense, "post-cinema" probably tells us less about the cinemas that are, those to come, and those that could be, than about the political economy of knowledge. The concept ultimately reflects the distanced analytical attitude of modern sciences and their corresponding discursive order. Its position coincides with the proverbial view of everything from nowhere available to the disembodied scholar. As it overlooks the insufficiency of cinema, the view from this position likewise disregards the experience of those charged with making the medium suffice. For most people working across film industries, cinema does not exist in itself. It is an overwhelming collective to be existed with. If a medium, as Krauss states, is indeed a recursive structure that is not a given, but made, the technicians and bureaucrats at the bottom of the hierarchy are the subjects at the core of its making. Theirs is the duty of preserving the conditions of mediation and equalizing any instance of the cinematographic work to every other. They must continually perform the translations that move "cinema" from the macro, abstract realm of what Latour called "decontextualized and depersonalized rationalities" 20 into specific, local realities - and vice-versa.

To work in the purification of signals means to soak in the grime of noise. From the subaltern position of the employees who move film copies around, check their quality, negotiate copyrights, procure equipment and authorizations, install plugins and configure software environments, coordinate data streams, maintain audio and video systems in order, moderate audience behaviour, keep the white cubes white and the dark rooms dark, turn the projector on at the start of the screening and off at the end, only to repeat everything on the following session, cinema is not a done deal. It is, rather, the continuing effect of management and invention, falling apart besides itself. The medium is a task never completely accomplished. It behaves as a complex organism, sporting most features that Shane Denson and Julia Leyda attribute to the post-cinematographic: interactive, networked, social, processual, aggregative, environmental, "among other things." ${ }^{21}$ The more precarious the circumstances, the more effort it requires to keep cinema together the more aware one must be of how contrived the medium's universal objectivity actually is.

\section{The view from the abyss}

\footnotetext{
${ }^{20}$ Bruno Latour, We have Never Been Modern, op. cit., p. 121.

21 Shane Denson \& Julia Leyda (dir.), Post-Cinema: Theorizing 21st-Century Film, Falmer, Reframe Books, 2016.
} 
Though constitutive of cinema, the maintenance practices described above are treated as largely inconsequential to the reality of the medium as a homogenous, exclusive totality. It is as if they did not achieve anything in themselves, only assisted the actual media operations to be carried out. Altogether, these practices stand in the negative of cinema. Their actors play a supporting cast, incapable of professional self-determination. Instead of creating work of their own, they merely prevent other people's work from breaking down. To understand the estrangement of these actors from the condition of proper media subjects, it might help to see what they do as a form of reproductive labor. Reproductive labor revolves around childbearing and raising, but also concerns housekeeping and caregiving work whose economic significance is often neglected. Feminist theory has mobilized the concept to bring light to the gendered division of labor between the industrious and domestic workforces. ${ }^{22}$ While the later creates conditions for the former to subsist, it is rarely accounted for in the costs and outcomes of social production. The traditional assignment of women to reproductive tasks perpetuates their subordination within patriarchal structures at large. Maintenance and care in the media industries does not revolve around the biological reproduction of the species, but rather around the sociotechnical reproduction of cultural work. These reproductive practices are not gendered in the same way as domestic labor but are similarly considered externalities without autonomy or value of their own.

Reproductive practices are inextricable from cinematographic work because they effectively sustain the work's continuity across time and space. They are nevertheless the invisible in invisible cinema, removed from the scope of disciplinary knowledge just as they would be from the proper media experience. Boaventura de Souza Santos describes how the metonymic reason of Western modernity premises the universality of its objects upon such invisibilities. ${ }^{23}$ After de Souza Santos, I would argue that film and media studies conventionally operate according to a form of abyssal thinking that "prevails by exhausting the field of relevant reality." 24 Reproductive practices, framed as the "disqualified parts of homogenous totalities that, as such, merely confirm what exists and precisely as it exists," 25 are the blind spots upon which modern conceptions of media systems are built. That means to say that film and media studies are not simply unable to acknowledge the relevance of reproductive practices, but actively produce them as nonexistent. The denial of reproductive worldviews is the condition for the affirmation of the positivity of the movie as an autonomous, individual entity, and of cinema as a selfcontained, stable field of sociocultural production.

Metonymic reason contracts the present while expanding the future. The epistemic appeal of the post-cinematographic grows the more one suppresses internal differences within cinema. Every agency that one discipline rejects might as well turn into the object of another, but any totality thus fabricated will be inevitably "less, not more, than the sum

\footnotetext{
${ }^{22}$ Karen Hansen \& Ilene Philipson (dir.), Women, Class, and the Feminist Imagination: A SocialistFeminist Reader, Philadelphia, Temple University Press, 1990. Silvia Federici, Caliban and the Witch: Women, the Body and Primitive Accumulation, New York City, Autonomedia, 2004.

${ }^{23}$ Boaventura de Sousa Santos, Epistemologies of the South: Justice Against Epistemicide, New York, Routledge, 2014.

${ }^{24}$ Boaventura de Sousa Santos, ibid., p. 118.

${ }^{25}$ Boaventura de Sousa Santos, ibid., p. 174.
} 
of its parts." 26 De Souza Santos urges us to recuperate the experiences wasted by metonymic reason in order to identify emancipatory possibilities. He calls for a twin sociology of absence and emergence that would "transform impossible into possible objects, absent into present objects" by inhabiting the oversights of Western monocultures. ${ }^{27}$ This project resonates across film and media studies through the dimension of reproductive practices. Just as de Souza Santos turns to forms of knowledge from the colonized South in search of global cognitive justice, one could engage with media reproductive practices in attempt to reach for the ontological multiplicity subsumed by the cinematographic apparatus. Located in the crux binding local circumstances to global abstractions - the irreducible particular to the exclusive universal -, reproductive practices are implied in a mode of committed awareness that reorient knowledge from the medium to the site. And cinema is infinitely larger from within.

A film and media studies of absence profits from scholarship that positivizes the negative. Research into foreign media industries foreground the partiality of hegemonic cinema. The exploration of distribution infrastructures both social and technical challenges the prerogatives of filmmaking in the production of any movie. What scholarship rarely does, however, is to undermine the exclusivity of its own credibility in making sense of reality. Academic work may salvage nonexistent objects from behind the abyssal lines of modern thinking (just like I'm doing right now), but it keeps these lines intact. The disciplinary order of knowledge must still come to terms with its own body-politics, which delegitimize thinking from subaltern positions. ${ }^{28}$ More than providing film and media studies with a wealth of analytical objects, reproductive practices embody situated perspectives from within the abyss. These perspectives are instrumental for the construction of a self-differential understanding of media, able to identify the reproduction of the conditions of mediation as the co-production of the medium itself. By inviting us to dwell in the negative instead of positivizing it, reproductive practices cultivate theorization in ways that destabilize subject-object relations and render the abyssal line of knowledge itself illegitimate.

I propose to appreciate reproductive practices within the sphere of the curatorial not only for the sake of professing my own commitments as a practitioner. I rather believe these fields unfold one another in compelling ways. The curatorial provides a key to approach reproductive practices that lends weight to their power over the access and subsistence of cultural work. But also, to underscore the reproductive-practical dimension of curation is to decouple it from the authority figures that colonize the popular imaginary of the profession and bring it the closer to the reality of most independent and assistant curators as precarious workers. Alexandra-Maria Colta, for example, shares a rare testimonial of the intellectual and emotional labor that goes in programming a film festival. ${ }^{29}$ The selection of works from an open call, while it may seem like a dilletante exercise, is a

\footnotetext{
${ }^{26}$ Boaventura de Sousa Santos, ibid., p. 167.

${ }^{27}$ Boaventura de Sousa Santos, ibid., p. 172.

28 Walter Mignolo, Local Histories/Global Designs: Coloniality, Subaltern Knowledges and Border Thinking, Princeton, NJ, Princeton University Press, 2000. Ramón Grosfoguel, "The Epistemic Decolonial Turn", Cultural Studies, no 21(2-3), pp. 211-223, 2007.

${ }^{29}$ Alexandra-Maria Colta, "Creative and Emotional Labour: Programming Human Rights Film Festivals as Practice-led Ethnography”, Alphaville: Journal of Film and Screen Media, n 17, 2019, pp. 128-145.
} 
calculus often done against adverse deadlines by an underpaid team, torn between taste judgement and concurrent institutional responsibilities. I had my taste of this experience while working in rogue movie screenings, unaffiliated with conventional media infrastructures. Curating, whether one realizes it or not, actualizes itself through a matrix of agents that performs the maintenance and care required to sustain the operational coherence of medium, preserving a universal noise-to-signal threshold while keeping the singularity of individual works.

The curatorial became a prominent field of knowledge production with the transformation of exhibitions into reflexive spaces, which O'Neill associates with the critical practice pioneered in the 1960 s by curator Seth Siegelaub. ${ }^{30}$ A recent anthology organized by O'Neill and Mick Wilson explores different ramifications of curating research, some more clearly aligned with modern sciences. ${ }^{31}$ However, and despite the professional overlaps evoked before, little has academia absorbed from these curatorial approaches. Within film and media studies, the growing interest for topics such as screen cultures, film festivals, and archives has indeed increased the attention paid to curating. As a form of scholarly activity, though, curating remains peripheral. While exhibitions represent a compelling way for scholars to share the movies they are working with, curatorial processes themselves are deemed irrelevant to academic research. The unspoken feeling is that curating may be useful for knowledge mobilization and management, but it does not advance our understanding of things in any significant way.

This low standing of the curatorial within modern hierarchies of knowledge is at odds with the status of curators as specialists. Simon Sheikh suggests curation falls short of scientific regimes of truth for the same reason as other social sciences sometimes do. ${ }^{32}$ The forms of survey particular to curation lean closer to journalistic recherché than to proper scientific Forschung: they gather evidence rather than test hypothesis under controlled conditions. For Sheikh, however, this would not justify reducing curation to the role of mediating research. He proposes that curatorial projects should perform as enacted research themselves. They could therefore be sites allowing for "the curatorial as political imaginary," able to carry out speculative propositions that create new logical, philosophical, aesthetical, and political possibilities. ${ }^{33}$

What may come from curation as an equivalent effort in cinematographic or medial imaginary? As it breaks away from expectations of impartiality, curating research is to become further implicated in the abyss of reproductive practices. Considering that curating, like pedagogy, entails "acting without fully knowing or being able to articulate what one is doing in advance," Karyn Sandlos remarks the chances of learning from the

\footnotetext{
${ }^{30}$ Paul O’Neill, “The Curatorial Turn: From Practice to Discourse”, op. cit.

${ }^{31}$ Paul O'Neill \& Mick Wilson (dir.), Curating Research, London, Open Editions, 2015.

${ }^{32}$ Simon Sheikh, "Towards the Exhibition as Research" dans Paul O’Neill \& Mick Wilson (dir.), Curating Research, London, Open Editions, 2015, pp. 32-46.

${ }^{33}$ Simon Sheikh, ibid., p. 40.
} 
works as well as learning in public. ${ }^{34}$ The laboratorial contingency of either white cube or dark room, already under Latourian suspicion, is thus put in active suspension. This suspension should not figure as a denial of mediation, however. On the contrary, it is a release of the medium's insufficiencies and excesses through reflexive forms of doingas-knowing. Making cinema otherwise, and seeing what sticks.

Understood in the guise of research-creation, curation integrates a history of what, following Natalie Loveless, ${ }^{35}$ I would describe as interventions in the academic politics of knowledge. Under many names, these interventions put into question not only who is authorized to know and what they are able to know, but also which modalities knowing may assume. The way research-creation rearticulates gestural boundaries between knowledge production and dissemination could be an antidote to the conventionally distant academic attitude. By dissolving categorical distinctions between knowing and doing, research-creation allows for a radical withdrawal from modern disciplinarity. Moreover, it invites us to deal in forms that welcome the dissonance of research objects.

While committed to the reproduction of cinema, one must participate in its innate multiplicity. The enactment of a screening, insofar it apprehends and exercises the performative reality of the medium, elicits a "practical ontology" - one within which, according to anthropologist Eduardo Viveiros de Castro, "knowing is no longer a way to represent the unknown, but rather to interact with it." 36 Viveiros de Castro invokes indigenous cosmopolitics to enrich continental philosophy with instruments that subvert the hierarchy of subject-object relations. Against the narrowing, multicultural notion of representation, he recuperates the Amazonian, multinatural concept of perspectivism. While the first calcifies an underlying, stable nature, the latter assents to the naturality of variation or, rather, to "variation as nature." 37 Curation, like perspectivism, inhabits a world in which transformation precedes form. As a radically intermediary practice, curation never works in itself. It always works for. More than filters, curators are information processors. They are cut to be community builders before gatekeepers. By effect of their willing subordination to multiple, often concurrent agencies, they must be simultaneously invested in equally multiple, embodied perspectives of the medium. That means to say that curators recognize cinema as a common meaning for multiple references. To enact a screening is to account - often unknowingly - for this ontological diversity: the medium, with all the stuff in.

Curatorial knowledge offsets reductive understandings of cinema not through authoritative discourse, but through unspoken insights scattered across the matrix of

\footnotetext{
${ }^{34}$ Karyn Sandlos, "Curating and Pedagogy in the Strange Time of Short Film and Video Exhibition", The Moving Image, $\mathrm{n}^{\circ} 4(1), 2004$, pp. 18.

${ }^{35}$ Natalie Loveless, How to Make Art at the End of the World: A Manifesto for Research Creation, Durham \& London, Duke University, 2019.

${ }^{36}$ Eduardo Viveiros de Castro, Metafísicas Canibais: Elementos para uma Antropologia Pós-Estrutural, São Paulo, n-1 edições, 2015, p. 111.

${ }^{37}$ Eduardo Viveiros de Castro, ibid., p. 69.
} 
reproductive labour. The awareness of structures of exclusion and the realities they deny leads to a fundamentally heretical relation with media, suspicious of media's normative representations. Curation embraces cinema's hybridity instead of proliferating its hybrids. The new and the other cease to be variations built on top of an exclusive totality and become plausible expressions of the medium as an engine of historical, cultural, and technological difference. The refusal of the easy progress expressed by the notion of postcinema means to inscribe both the research and reproduction of cinema within what de Souza Santos calls an axiology of care. ${ }^{38}$ To take responsibility for the abundant variance of the world is a step towards liberating the present from subjection to a certain future, whether through the redistribution of resources or the disruption of knowledge/power articulations. Concrete possibilities of emancipation lie behind the abyss of modern knowledge: cinema as insurgence, ready to be cultivated.

\footnotetext{
${ }^{38}$ Boaventura de Sousa Santos, Epistemologies of the South: Justice Against Epistemicide, op.cit.
} 